\title{
Wider das Vor-Recht des Narrativen
}

\section{Otfried Höffe}

Professor für Philosophie an der Universität Tübingen, Präsident der Nationalen Ethikkommission im Bereich der Humanmedizin
Einem Widerspruch darf man seinerseits widersprechen: Nein, es trifft nicht zu, wie Johannes Fischer gegen mein Plädoyer für die moralphilosophische Notwendigkeit von Begriffen und Prinzipien behauptet, der Gehalt des Begriffes der Menschen lasse sich «nicht ohne den Rekurs auf die Anschauung bzw. Vorstellung von Verletzungen bestimmen, die Menschen zugefügt werden können».

Johannes Fischer hat mit der These fraglos recht, die Menschenwürde lasse sich nicht auf das Recht festlegen, eigentlich sogar verkürzen, «nicht erniedrigt, d.h. in seiner Selbstachtung nicht verletzt zu werden». Rückfragen drängen sich aber schon beim «d.h.» auf. Denn im angeblichen Gegenbeispiel findet sehr wohl eine Erniedrigung, aber vielleicht keine Verletzung von Selbstachtung statt.
Zur (moralischen) Didaktik gehört es, den Gegenstand plastisch vor Augen zu führen. Und eine (moralische) Didaktik-Rhetorik soll den Leser oder Zuhörer bei seinen Erfahrungen und seinen Emotionen, einschliesslich der (hoffentlich vorhandenen) Empathie «abholen». Im Fall von Menschenrechtsverletzungen soll man durchaus zu einem engagierten Protest «emotionalisiert» werden: Ein derartiges «himmelschreiendes Unrecht» darf nicht sein.

Seit Platon und Aristoteles und nicht bloss bis Kant, verstehen die wahrhaft grossen Denker die Moralphilosophie als eine praktische Philosophie. Sie wollen letztlich, freilich stets modo philosophico, also mittels Begriff und Argument, gelegentlich auch mit Gedankenexperimenten und lebensnahen Beispielen, dem Handeln, und zwar moralischen Han-

\section{Begriffe bestimmen etwas Allgemeines; sie gelten für eine Vielzahl von Aspekten oder Falltypen und für eine noch grössere Zahl von Einzelfällen}

Der grösste Philosoph der Menschenwürde, Immanuel Kant, nennt bekanntlich ein anderes Kriterium: Der Mensch hat das Recht, niemals bloss als Mittel, er muss vielmehr stets auch als Zweck behandelt werden. (Die Autonomie im strengen Sinn, die Selbstgesetzgebung des Willens, benennt «nur» das subjektive Prinzip: Wozu muss das Subjekt fähig sein, das wahrhaft moralisch handelt?). Zweifellos verstösst gegen das Selbstzweckgebot, wer mit Lastwagen über Gefangene hinwegfährt, und zwar gleichgültig, ob sie Muslime, Christen oder Atheisten sind: Der Mensch bloss, weil er Mensch ist, hat den Anspruch, anders behandelt zu werden. Begriffe bestimmen etwas Allgemeines; sie gelten für eine Vielzahl von Aspekten oder Falltypen und für eine noch grössere Zahl von Einzelfällen. deln dienen. Deshalb begnügen sie sich nicht mit Prinzipien, Kant also nicht mit der Autonomie des Willens und dem kategorischen Imperativ. In einer bis heute vorbildlichen Weise reflektieren sie argumentativ und zugleich lebenserfahren und erfahrungsgesättigt.

Dass nicht wenige zeitgenössische Moralphilosophen diese Fähigkeit verloren haben oder sie sogar bewusst als angeblich unphilosophisch diskreditieren, trifft leider zu. Dagegen, gewissermassen als Kontrapunkt, narrative Elemente einzubringen, dürfte sinnvoll sein. Sie sind aber keine veritable Alternative, kein Stattdessen, das ein Vor-Recht, vielleicht sogar ein Exklusivrecht beanspruchen dürfte. 